\title{
A NEW TECHNIQUE - NEAR MINIMUM MATERIAL ZONE, TO REDUCE THE WEIGHT OF THE COMPONENTS IN MACHINING
}

\author{
Ganesh Kumar $\mathbf{N}^{1}$, Selvaraj $\mathbf{P}^{2}$, Radhakrishnan $\mathbf{P}^{3}$ \\ ${ }^{1}$ Assistant Professor (SG), Department of Mechanical Engg., PSG College of Technology, India, gkncbe@yahoo.com \\ ${ }^{2}$ Group Director, CAD \& PLM-PM, ADA, selvaraj.pon@gmail.com \\ ${ }^{3}$ Director, PSGIAS, rkp_n@yahoo.com
}

\begin{abstract}
Customers buy a product when the quality of the product is high. So manufacturers produce their components to high quality. The product such as aircraft, automobile, motorcycle, etc. not only need to be produced at high quality but also at reduced weight. This is because these products performance is depend on weight of the product. A component could consist of several components. So all relevant component weights are reduced, then the overall weight of the component could be reduced. This paper introduces as new technique called "near minimum material zone" where not only the weight of the component could be reduced but also helps to increase the quality. To demonstrate this technique, two sets of experiments with 20 samples were conducted using Deckel Maho CTX310 ECO VI CNC machine. The first experiment was conducted under normal machining condition. The second experiment was conducted under this new technique. Several tools such as process capability analysis (Cp, Cpk), cause and effect diagram, X Hi/Lo and R-charts were used to analyze the case study data. The paper outcome suggests that this new technique not only helped to control the weight of the components but also improved the desired quality by minimizing the dispersion of the component dimensions to obtain higher sigma level.
\end{abstract}

Keywords: Near Minimum Material Zone, Process Capability, Cpk, Cause and Effect diagram, X Hi/Lo chart, $R$ chart, Quality.

\section{INTRODUCTION}

In recent years, global competition has changed the fundamental requirements in defining a quality in manufacturing industry. The customers dedicates the product sales, which is directly related to product quality. Therefore, to sustain the product sales, manufacturers are forced to produce a high quality products. Traditionally, when a component is machined and the dimensions falls within the tolerance band (upper control limit and lower control limit), then that part is said to be good quality product (black dots in Figure 1). However, due to high competitions, manufacturers are force to produce their products closer to the targeted mean (blue triangle in Figure 1). Taguchi [1] point out that keeping the part process variability close to the target values requires continuous monitoring and adjustments to the manufacturing processes during the production cycle.

In this paper, a new technique called "near minimum material zone" was introduced to demonstrate how the component targeted dimension could be moved closer to target mean by shifting the means. The outcome of this technique is it helps to reduce the weight of the component and able to machine the components at higher quality levels. This technique could be applied to any industry, where the weight of the component should be reduce and at the same time, the quality of the product should be improved.

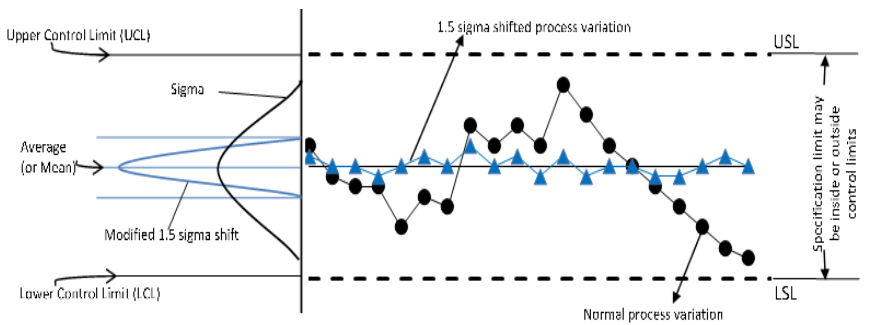

Fig.1. Process variations under normal and "near minimum material zone" conditions

Aircraft is made of several components such as ribs, spars, brackets, etc. The rib is the chord-wise member of the wing structure of an aircraft, which used to give the wing section its form and to transmit the load from the fabric to the spars. By, analogy with the anatomical definition of a "rib" is that the ribs attach to the main spars, and by being repeated at frequent intervals, from a skeletal shape for the wing. Usually, the ribs incorporate the airfoil shape of the wing, and the skin (composite materials) adopts over the ribs. Figure 2 shows the jack rib component of a aircraft wing. 


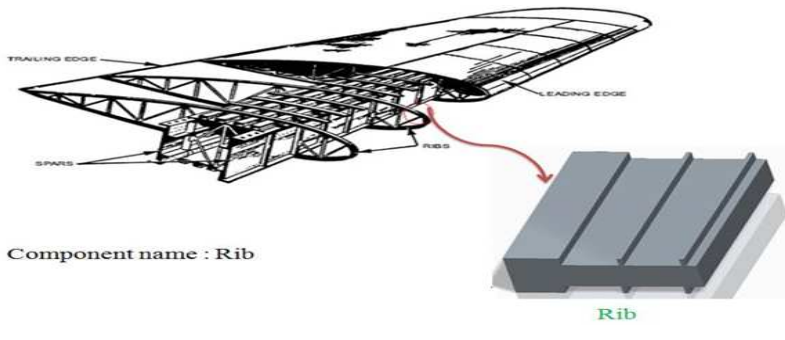

Fig 2 Aerospace rib component

Similarly, this technique could be applied to automobile and motorcycle industry, where the weight of the components needs to be reduced. Figure 3 and 4 illustrates some of the automobile and motorcycle components.
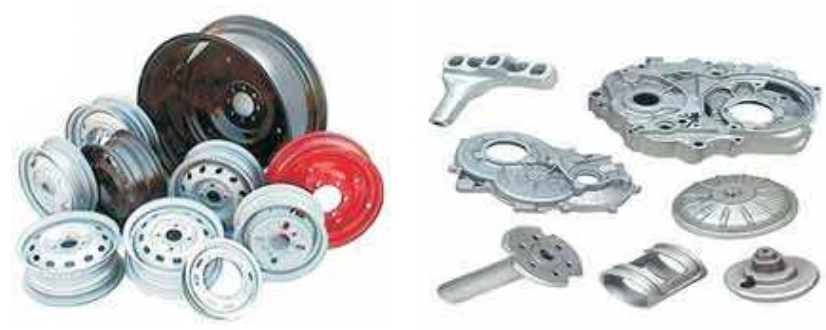

Fig 3. Automobile components.
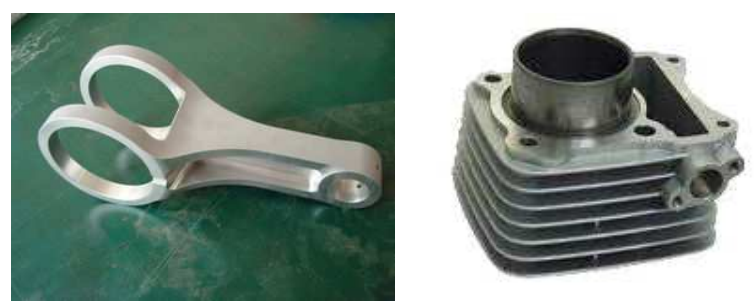

Fig 4. Motorcycle components.

Aluminum alloys are widely used metal in many aircraft, automobile and motorcycle structural components. The reasons for this selection are its low cost, light-weight, and modern appearance. Most of these structural components have complex geometry and they need to be machined with high precision and dimensional accuracy. Currently, CNC machine tools are used to machine these components. Despite this, with the current technology, achieving this geometric dimensional accuracy on consistent basis is a difficult task. In addition, achieving this dimensional accuracy on machining the same component (assume that the component is lengthier) throughout the complete machining cycle is also difficult.
The component process variability could be occurring due to two main factors: deterministic and randomization. The deterministic factors such as spindle speed, feed, depth of cut, etc. are the ones which could be predicted easily and it can be controlled. However, the randomization factors such as thermal gradients, vibrations, etc. are unpredictable and it is very difficult to control. The randomization factors cannot be eliminated completely, but could be minimized. Automation is one method, which could aid to minimize this gap. Siemens [2] suggest that automation helps to increase the quality of manufacturing process and reduce investment costs by $20 \%$.

\section{BACKGROUND}

The final product (for example, aircraft, automobile, motorcycle) is composed of one or more sub-components. The weight of each sub-component contributes the overall weight of the final product. Therefore, it is very importance to control the weight of the each component. The weight of the aircraft impact the flying ability such as longer take-off distance, shorter range, higher stalling, higher landing speed, reduced rate and angle of climb, reduced cruising speed, longer landing distance and higher take-off speed [3][4]. Similarly, reducing the weight of the components save fuel costs [3][5][6][8]. Reducing the weight of each component even by small percentage shall contribute the overall performance of a system. Kaw [5] reported that reducing $0.453 \mathrm{~kg}$ of mass in a commercial aircraft saves up to 1360 liters of fuel each year. This paper reveals the new technique called "near minimum material zone" to control the weight of the components and able to machine the components within the tolerance band with desired quality level.

For the past twenty two years, process capability analysis was and being used as one of the tools in statistics process control (SPC) for continuous improvement in quality and productivity. It helps to determine whether the parts are within the tolerance limits and engineering specifications [10]. The process capability index (PCI) is used to measure the capability of a process are $\mathrm{Cp}, \mathrm{Cpk},[15]$. Cp is widely used by the industry to check the capability of production process [11]. It does not deal with cases where process mean is not centered [13]. This drawback is overcome by Cpk. The Equations (1) to (7) depicts the $\mathrm{Cp}$ and $\mathrm{Cpk}$ formulas.

$$
\mathrm{C}_{\mathrm{p}}=\frac{(\mathrm{USL}-\mathrm{LSL})}{6 \sigma}
$$

2-sided Specification Limits:

$$
\begin{gathered}
\mathrm{C}_{\mathrm{pk}}=\operatorname{Minimum~}\left[\mathrm{C}_{\mathrm{pku}}, \mathrm{C}_{\mathrm{pkl}}\right] \\
\mathrm{C}_{\mathrm{pku}}=\frac{(\mathrm{USL}-\mu)}{3 \sigma} \\
\mathrm{C}_{\mathrm{pkl}}=\frac{(\mu-\mathrm{LSL})}{3 \sigma}
\end{gathered}
$$

\section{1-sided Specification Limits:}




$$
\begin{gathered}
\mathrm{C}_{\mathrm{pk}}=\mathrm{Cpk}_{(\max )} \text { or } \mathrm{C}_{\mathrm{pk}(\min )} \\
\mathrm{C}_{\mathrm{pk}(\max )}=\frac{(\mathrm{USL}-\mu)}{3 \sigma} \\
\mathrm{C}_{\mathrm{pk}(\min )}=\frac{(\mu-\mathrm{LSL})}{3 \sigma}
\end{gathered}
$$

A process is said to be a centred distribution or process when $\mathrm{Cp}=\mathrm{Cpk}$, otherwise it is said to be a not-centred distribution or process. Winton [16] clearly illustrated that the process capability (Cpk) gradually reduces (even goes to a negative value) when the mean is shifted while the variation $(\mathrm{Cp}$ and $\sigma)$ remains the same.

\section{A NEW TECHNIQUE - NEAR MINIMUM MATERIAL ZONE}

A new technique called "near minimum material zone" was introduced to control the material zone and at the same time, the desired quality output would be achieved. To explain this concept, an aerospace component was taken as an example and it was machined using "near minimum materials zone" technique, where the weight of the component was reduced and at the same time, the quality of the component was improved. For a given machining condition, there could be two machining scenarios: (a) what strategy to use when machining the inner dimension of the component; (b) what strategy to use when machining the outer dimension of the component.

\subsection{Scenario 1}

Machining the inner dimensions of a component (ex. hole of a component) For this, machine the component to the upper limit of the control chart. This is illustrated in Figure 5.

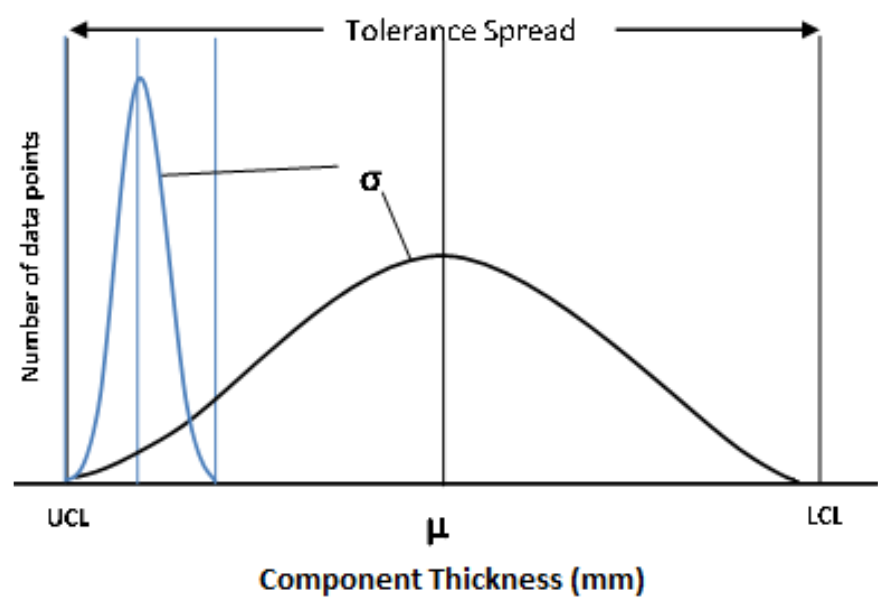

Fig.5. "Near minimum material zone" condition for inner dimension.

\subsection{Scenario 2}

Machining the outer dimensions of a component (ex. shaft) For this, machine the component to the lower limit of the control limit, which is illustrated in Figure 6.

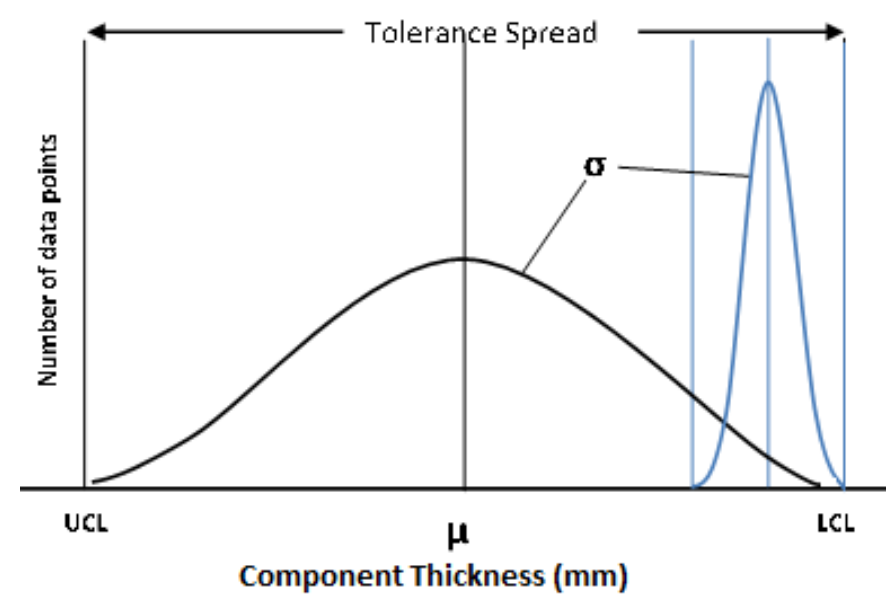

Fig.6. Near minimum material zone requirement for outside dimension.

In both the scenarios, the desired outcome was to minimize the dispersion of component dimension (reduced sigma spread).

From Figures 2 and 3, it was clear that the target mean was shifted closer to the desired UCL or LCL. In other words, when machining an outer dimension of the component, shift the target mean closer to LCL. Similarly, when machining an inner dimension of the component, shift the targeted mean closer to UCL. When the process capability study was conducted under both scenarios, the $\mathrm{Cp}$ and $\mathrm{Cpk}$ values may be very low or even negative. This is because the $\mathrm{Cp}$ and $\mathrm{Cpk}$ equations (Equations 1 to 7 ) were calculated under normal condition, where targeted mean $(\mu)$ was not shifted.

When near minimum material zone condition was applied, then targeted mean $(\mu)$ was shifted based on the above scenarios. Therefore, the $\mathrm{C}_{\mathrm{p}}$ and $\mathrm{C}_{\mathrm{pk}}$ formulas were modified, which were depicted in Equations 8 to 10.

$$
\begin{gathered}
\mathrm{C}_{\mathrm{p}(\mathrm{m})}=\frac{([\mathrm{USL}-(\mathrm{USL}) \mathrm{m}]-[\mathrm{LSL}-(\mathrm{LSL}) \mathrm{m}])}{6(\sigma-(\sigma) \mathrm{m})} \\
\mathrm{C}_{\mathrm{pku}(\mathrm{m})}=\frac{(\mathrm{USL}-(\mathrm{USL}) \mathrm{m})-(\mu-(\mu) \mathrm{m})}{3(\sigma-(\sigma) \mathrm{m})} \\
\mathrm{C}_{\mathrm{pkl}(\mathrm{m})}=\frac{(\mu-(\mu) \mathrm{m})-(\mathrm{LSL}-(\mathrm{LSL}) \mathrm{m})}{3(\sigma-(\sigma) \mathrm{m})}
\end{gathered}
$$

The process flow chart of a machining process is depicted in Figure 7. 


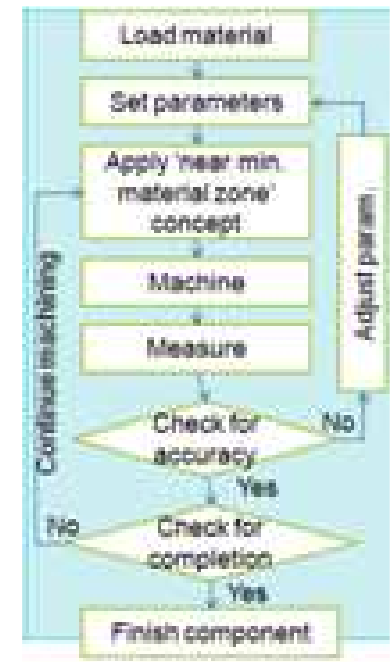

Fig 7. Process flow chart of a machining process.

\section{EXPERIMENTS}

A simple experiment was conducted to machine a raw work piece diameter of $24 \mathrm{~mm}$ in Deckel Maho CTX310 ECO VI CNC Lathe. The work piece was machined to $20 \mathrm{~mm}$ diameter with h6 $(+0.037$ and +0.059$)$ tolerance specifications. The brand new carbide tool tip - ZCC 120408 and ZCC 120404 were used for rough and finish machining respectively. According to vendor specifications and PSG data book [24], the spindle speed was set at $1300 \mathrm{rpm}$ and $3000 \mathrm{rpm}$ for rough and finish cut respectively. Similarly, the feed rate was set at $0.2 \mathrm{~mm} / \mathrm{rev}$ and $0.11 \mathrm{~mm} / \mathrm{rev}$ for rough and finish cut respectively. The depth of cut was set to 0.4 for finish cut. The same operator was engaged throughout the study. The NC codes were programmed with targeted mean (20.048) and 20 work piece (samples) were machined. For each sample, five data points were measured. Thus, 100 data points were collected. Table 1 illustrates the sample data collection.

The collected sample data was verified against the normally distributed population (within tolerance spread) using normality test. Minitab was used to analyze the data. Figure 8 illustrates the normality test result for the collected sample.

Table 1 Sample data collection of the experiment \#1

\begin{tabular}{|l|l|l|l|l|l|}
\hline \multirow{2}{*}{$\begin{array}{l}\text { Sa } \\
\text { mpl } \\
\text { e }\end{array}$} & \multicolumn{5}{|l|}{ Measured data points } \\
\hline 1 & 20.047 & 20.046 & 20.046 & 20.046 & 20.046 \\
\hline 2 & 20.042 & 20.044 & 20.042 & 20.046 & 20.046 \\
\hline 3 & 20.044 & 20.041 & 20.042 & 20.043 & 20.042 \\
\hline 4 & 20.045 & 20.043 & 20.045 & 20.041 & 20.044 \\
\hline 5 & 20.046 & 20.045 & 20.046 & 20.047 & 20.046 \\
\hline 6 & 20.049 & 20.043 & 20.042 & 20.044 & 20.043 \\
\hline 7 & 20.047 & 20.048 & 20.048 & 20.046 & 20.046 \\
\hline
\end{tabular}

\begin{tabular}{|l|l|l|l|l|l|}
\hline 8 & 20.046 & 20.050 & 20.047 & 20.048 & 20.047 \\
\hline 9 & 20.045 & 20.044 & 20.044 & 20.046 & 20.045 \\
\hline 10 & 20.043 & 20.044 & 20.049 & 20.046 & 20.044 \\
\hline
\end{tabular}

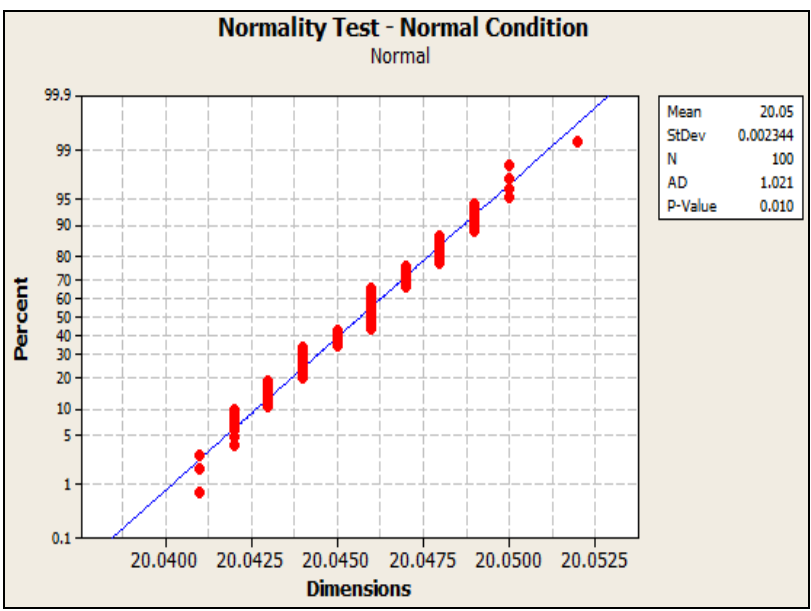

Fig 8. Normality test of the sample data.

The mean of the sample data was 20.05 and the standard deviation was 0.002344 . Using a significance level of 0.05 , the Anderson-Darling normality test $(\mathrm{P}$-value $=0.01)$ indicates that the dimensions measured do not follow a normal distribution. In other words, the null hypothesis test is rejected. Figure 9 illustrates the distribution and variation of process dataset, in histogram graph. This helps to identify which dataset was closer to UCL and LCL. Thus, appropriate actions could be taken in improve phase of the lean six sigma roadmap.

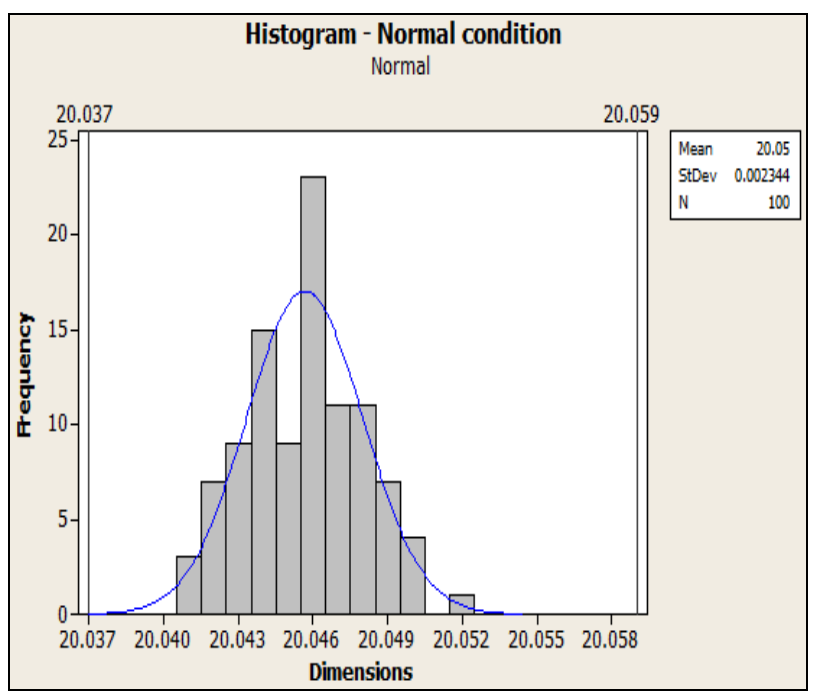

Fig.9 Histogram of the sample data. 


\subsection{Process Capability Study}

The process capability study was an excellent method for determining the rate of failure and stability on measurable processes. The higher the $\mathrm{Cpk}$, the more stable the process. Figure 10 illustrates the process capability study of the collected sample data.

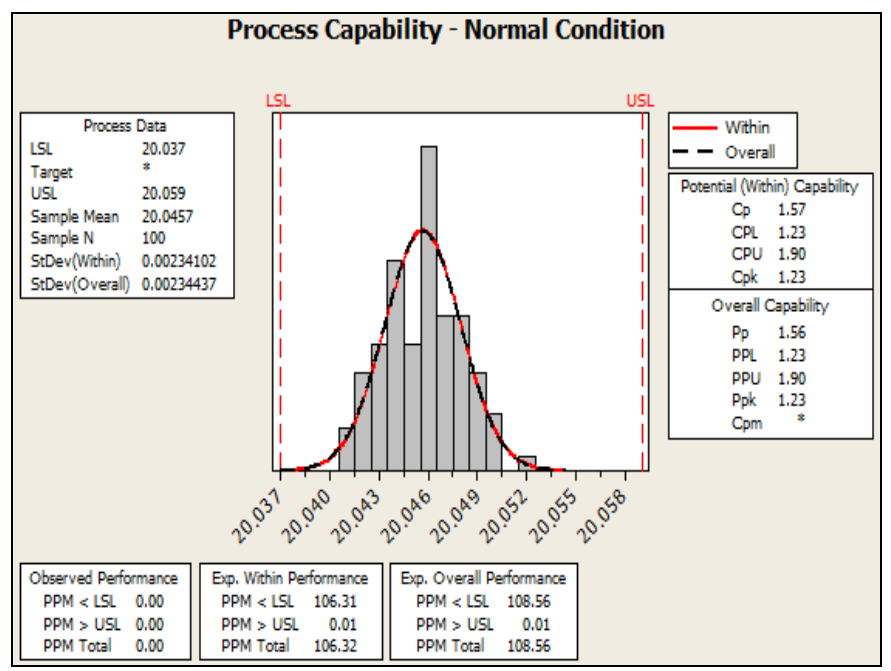

Fig 10. Process capability study of the sample data.

The $\mathrm{Cp}$ and $\mathrm{Cpk}$ for the given study was 1.57 and 1.23 respectively. It was important to note that the $\mathrm{Cpk}$ value was more than one. This tells that the variation in the process is good. In addition, $\mathrm{Cp}$ value was close to $\mathrm{Cpk}$ value; therefore, the quality of the process was also good.

\subsection{X-Bar Hi/Lo and R-Charts Analysis}

Doering [25] describe true distribution for precision machining shall be continuous uniform or rectangular distribution. He suggested X-bar Hi/Lo and R chart would be appropriate for precision machining applications. The X-bar Hi/Lo chart shows the relationship between high and low values, whereas the R-chart study shows the closeness of the readings. In other words, it represents the roundness of the data collection. Doering suggested that when the roundness value falls within $10 \%$, then the machining is considered as precision machining. The capability of the process could be calculated as below:

$$
\text { Capability }=\frac{(\mathrm{USL}-\mathrm{LSL})}{(\mathrm{UCL}-\mathrm{LCL})}
$$

Figure 11 illustrates the $\mathrm{X}$-bar $\mathrm{Hi} / \mathrm{Lo}$ and $\mathrm{R}$ - charts for the normal condition. The upper specification limit and lower specification limit (tolerance band) was set at 20.059 and 20.037 respectively (representing the green dotted line in Figure 11). The upper control limit and lower control limit was set at $75 \%$ of the tolerance (20.056 and 20.040), representing the blue dashed line in Figure 11. The roundness (range limit) was calculated as $0.022 \mathrm{~mm}$.

From the Figure 11, it was noted that all the data collected were within $75 \%$ of the control limit. The above values are plugged into equation 11 , which leads to 1.375 .

$$
\text { Capability }=\frac{(20.059-20.037)}{(20.056-20.040)}=1.375
$$

It was interesting to note that R-chart tolerance falls within $15 \%$, which means some variations exists during machining. This led to cause and effect analysis, which is covered in next section.

The second set of experiment was conducted to demonstrate the "near minimum material zone" technique. In this, the factors such as operator negligence, tools were gauged, use of old tool, etc. (listed in Figure 12) were controlled. It was assumed that factors such as temperature, humidity, etc. do not impact the study. 

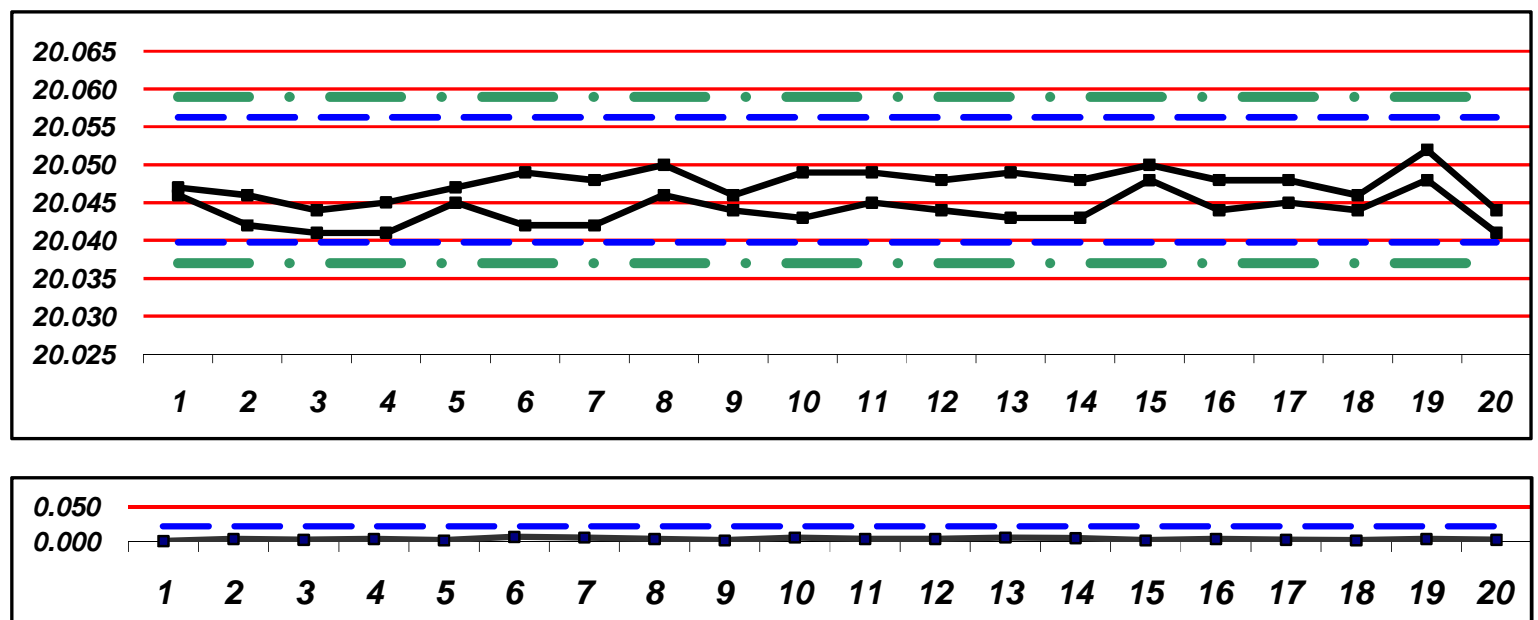

Fig 11. X-bar Hi/Lo and R-charts for Normal condition

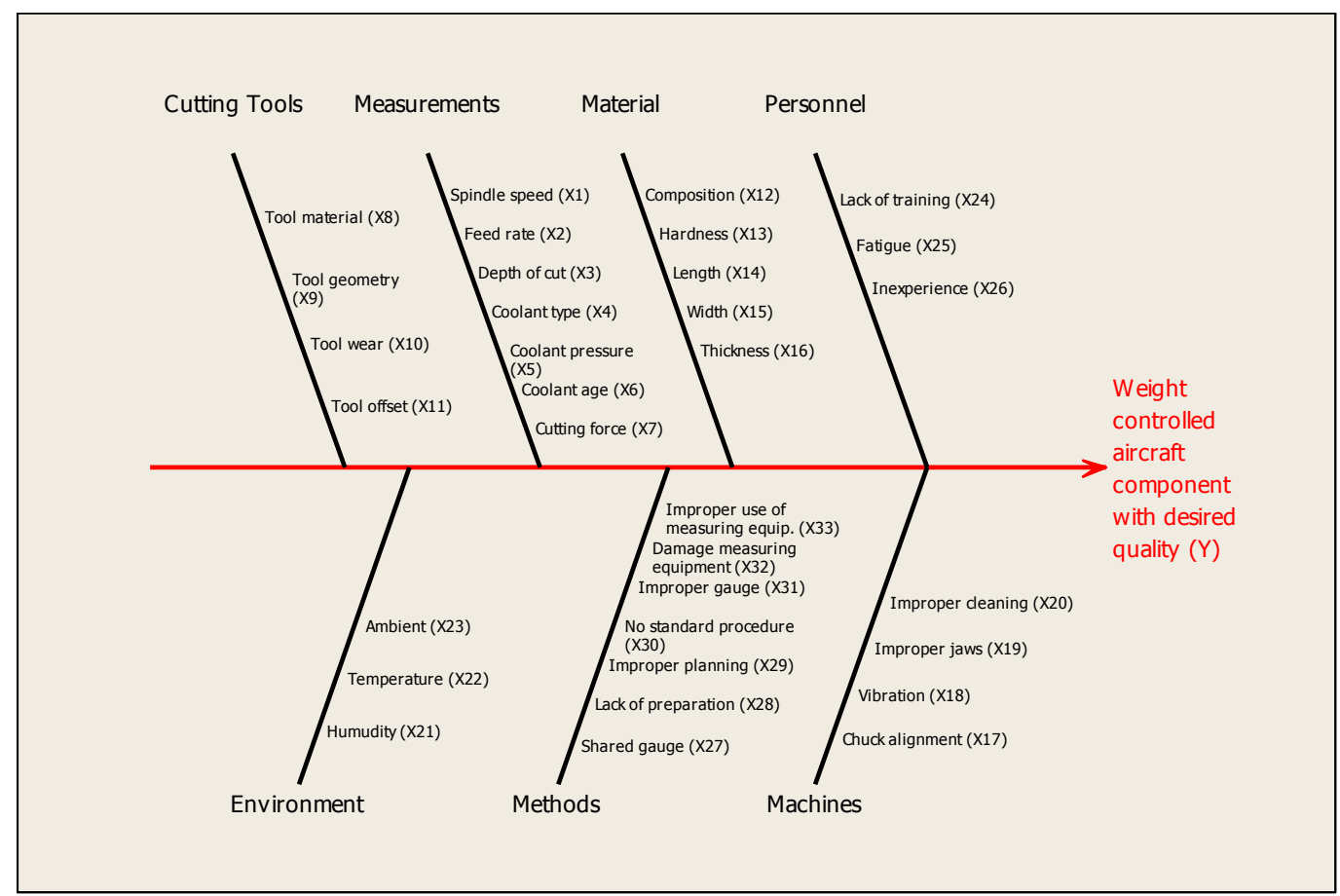

Fig 12. Cause and effect diagram to determine the factors affecting the weight control of the compoent.

The case study which was considered was to machine on the outside of the component. Therefore, scenario 2 was considered. In this scenario, the targeted mean $(\mu)$ was shifted closer to the lower control limit.

Similar experiments were carried out but with a shifted targeted mean (20.041). The speed, feed and depth of cut were used as similar to the previous experiments. The same operator machined was engaged in this experiments as well. The NC program was created based on the above specifications and new 20 work piece samples were machined. For each sample, again five data points were measured. Thus, 100 more data points were collected, which was similar to Table 1.

The capability formula (equation 11) may not work for this "near minimum material zone" condition because of shifted 
targeted mean. Therefore, the process capability formula was modified to this condition:

$$
\text { (Capability)m }=\frac{(\{\mathrm{USL}-(\mathrm{USL}) \mathrm{m}\}-\{\mathrm{LSL}-(\mathrm{LSL}) \mathrm{m}\})}{(\{\mathrm{UCL}-(\mathrm{UCL}) \mathrm{m}\}-\{\mathrm{LCL}-(\mathrm{LCL}) \mathrm{m}\})}
$$

For this new condition, the upper specification limit and lower specification limit (tolerance band) was set at 20.045 and 20.037 respectively (representing the light green dashed line in Figure 13). The upper control limit and lower control limit was set at $75 \%$ of the tolerance (20.044 and 20.038), representing the red dotted line in Figure 13. The roundness (range limit) was calculated as $0.008 \mathrm{~mm}$.
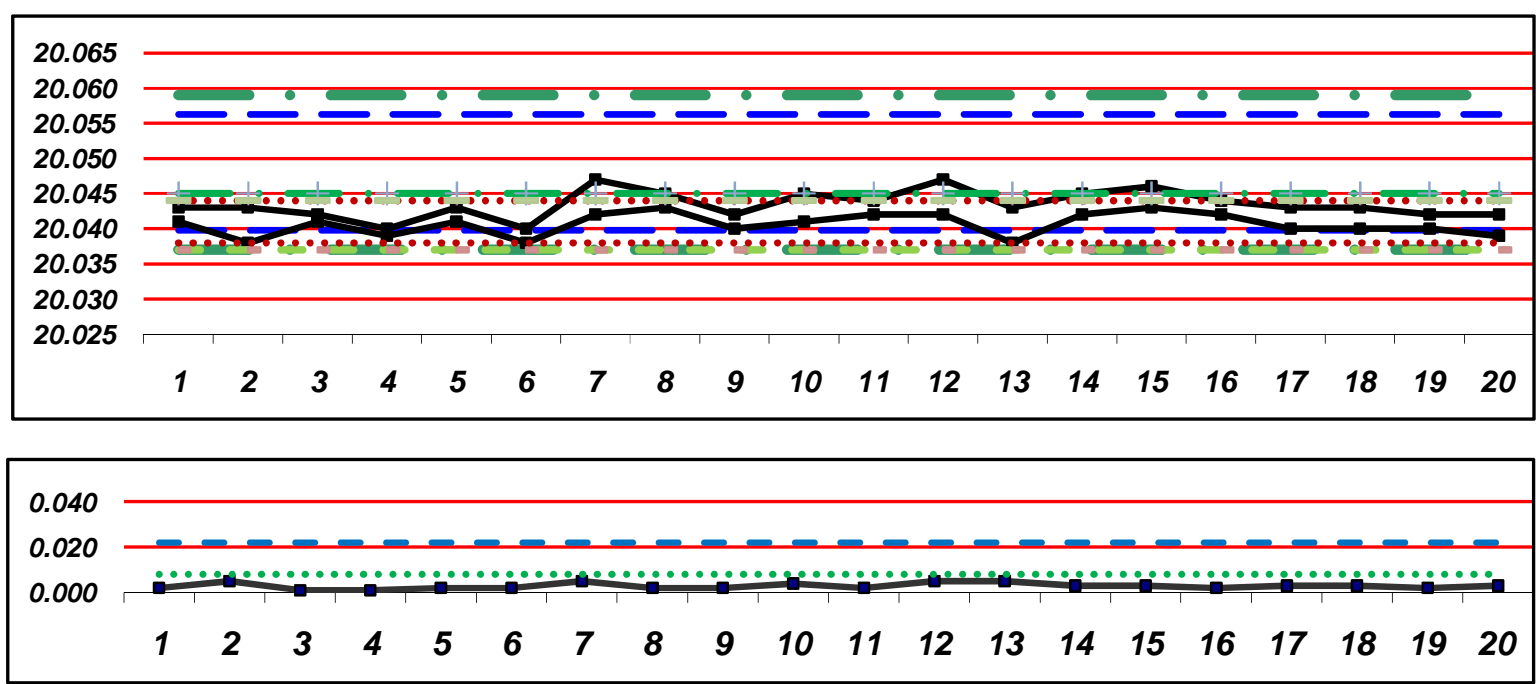

Fig 13. X-bar Hi/Lo and R-charts with "near minimum material zone" condition.

From the Figure 13, it was noted that still all the data collected were within $75 \%$ of the control limit. The above values are plugged into equation 12 , which leads to 1.411 .

$$
\text { (Capability)m }=\frac{[(20.059-20.037)]-[(20.037-20.037)]}{[(20.056-20.044)]-[(20.040-20.038)]}=1.411
$$

It was interesting to note that R-chart tolerance falls within $10 \%$, which means the machining was performed well.

Table 2 illustrates the comparison of parameters between normal and "near minimum material zone" conditions.

Table 2. X-bar Hi/Lo and R-chart specifications for Normal and "near minimum material zone" conditions.

\begin{tabular}{|lll}
\hline Specification Limits & Normal & Shifted \\
\hline Upper Spec Limit & 20.059 & 20.045 \\
Lower SpecLimit & 20.037 & 20.037 \\
\hline Control Limits & & \\
Upper Control Limit & 20.056 & 20.044 \\
Lower Control Limit & 20.040 & 20.038 \\
Range limit & 0.022 & 0.008 \\
Capability & & \\
Relative Index & 1.375 & 1.411 \\
\hline
\end{tabular}

\section{CONCLUSIONS}

The new technique called "near minimum material zone" was introduced in this paper. To prove this concept, an application was chosen. With this technique, it was demonstrated that the weight of the component (in this case study - aerospace component) in machining could be reduced and this technique also aided to improve the quality of the component. For, this two sets of experiments were carried out The first experiment was to machine the components using normal methodology. Process capability study, cause and effect diagram, X-bar $\mathrm{Hi} /$ Lo R-charts etc. were used for data analysis. The Cpk value for normal condition was determined. The second experiment was conducted using "near minimum material zone" technique. Identical setups were arranged and the data were analyzed. The Cpk value for "near minimum material zone" technique was also determined. The findings of this paper was that the weight of the components were reduced and the quality of the machining was improved significantly (see Table 2).

\section{REFERENCES}

[1]. G. Taguchi, E. A. Elsayed and T. H. Siang, 1989, Quality Engineering in Production Systems, McGraw-Hill International Editions, Engineering Series Siemens. 2011. Non-stop Manufacturing Excellence-Automotive: Answers 


\begin{tabular}{|c|c|}
\hline $\begin{array}{l}\text { for industry, } \quad \text { Siemens } \\
\text { http://www.automation.siemens.com/mcms/automotive- } \\
\text { manufacturing/Documents/br_cca_en.pdf }\end{array}$ & $\begin{array}{l}\text { VIT University, India in } 2009 \text {. He has more than } 10 \\
\text { publications in various Journals and Conferences. }\end{array}$ \\
\hline $\begin{array}{l}\text { [2]. Author unknown, 1975, Weight Control of Aircraft, } \\
\text { Department of Transport, AustraliaReilly Burke, 2005, Weight } \\
\text { and balance and airplane performance, ATP Inc Kaw T., } 2012 .\end{array}$ & $\begin{array}{l}\text { Radhakrishnan P - Currently, the author is working as } \\
\text { Director of PSG Institute of Advanced Studies, Coimbatore, } \\
\text { India. He is also working as visiting Professor in Mechanical }\end{array}$ \\
\hline $\begin{array}{l}\text { Mechanics of composite materials, Taylor \& Francis } \\
\text { Publications }\end{array}$ & $\begin{array}{l}\text { Engineering department, PSG College of Technology, } \\
\text { Coimbatore, India. Prior to this, he worked as Vice Chancellor }\end{array}$ \\
\hline [3]. Author unknown, 2013. Technological and Economics & of VIT, Principal of PSG College of Technology, India and \\
\hline Potential of Greenhouse Gas - Mitigation, Intergovermental & Professor of PSG College of Technology, India. He is working \\
\hline Panel of Climate $\quad$ Control. & in teaching field for more than 30 years and has more than 50 \\
\hline $\begin{array}{l}\text { http://www.ipcc.ch/ipccreports/tar/wg3/index.php } \\
\text { [4]. Steven A Morrison, 1984. An economic analy }\end{array}$ & $\begin{array}{l}\text { publications in International Journals and International } \\
\text { Conferences. }\end{array}$ \\
\hline
\end{tabular}
design, Journal of Transport Economics and Policy, May, pp. 123-143.

[5]. Pietro Cerrellera, 2007. Reducing weight in aircraft structures, Altair Hyperworks in Action - Webinar Series, Altair engineering, Inc.Ali Riza Motorcu and Abdulkadir Gullu, 2004. Statistical process control in machining, a case study for machine tool capability and process capability, Journal of materials \& design, 27, pp. 364-372.

[6]. Abbas Al-Refaie, and Nour Bata, 2010. Evaluating measurement and process capabilities by GR\&R with four quality measures, Journal of Measurement, 43, pp. 842-851.

W. L. Pearn, and P.C. Lin, 2004. Testing process performance based on capability index Cpk with critical values, Journal of Computers \& Industrial Engineering, 47, pp. 351-369.

[7]. Chien-Wei Wu, W. L. Pearn, and Samuel Kotz, 2009. An overview of theory and practice on process capability indices for quality assurance, International Journal of Production Economics, 117, pp. 338-359.

[8]. K. S. Chen, K. T. Yu, and S. H. Sheu, 2006. Process capability monitoring chart with an application in the siliconfiller manufacturing process, International Journal of Production economics, 103, pp. 565-571

[9]. M. Suozzi and Don Winton, 1999. Process Capability Studies, Hughes Aircraft Company, Arizona.

[10]. PSG, 2013. "PSG Data Book", PSG College of Technology, India PSG Data Book website: http://www.psgdesigndata.org/

\section{BIOGRAPHIES:}

Ganesh Kumar N - Currently, the author is working as Assistant Professor (SG) in Mechanical Engineering department, PSG College of Technology, Coimbatore, India. $\mathrm{He}$ is pursuing his $\mathrm{PhD}$ in Automation and Robotics in Anna University (India) under the guidance of Dr P Radhakrishnan. The author has completed three Master's degree from United States and has fifteen years of manufacturing plant floor experiences in Automobile industry in United States.

Selvaraj P - Currently, the author is working as Group Director of CAD \& PLM-PM, Aeronautical Development Agency (ADA), Bangalore, India. He worked in various department of ADA since 1987. He received his Doctoral from 